\title{
Pineal gland calcification confirmed by CT scan is associated with ischemic stroke
}

\author{
Yaser Moadabi ${ }^{1,2}$, Metanat Rezaei ${ }^{3}$, Enayatollah Homaei-Rad ${ }^{4,5}$, Sima Fllah Arzpeyma ${ }^{6}$, \\ Sama Noroozi Guilandehi ${ }^{3}$, Sasan Andalib2,5,7 \\ ${ }^{1}$ Department of Neurology, Poursina Hospital, School of Medicine, \\ Guilan University of Medical Sciences, Rasht, Iran \\ ${ }^{2}$ Neuroscience Research Center, Poursina Hospital, School of Medicine, \\ Guilan University of Medical Science, Rasht, Iran \\ ${ }^{3}$ School of Medicine, Guilan University of Medical Sciences, Rasht, Iran \\ ${ }^{4}$ Social determinants of Health Research Center, \\ Guilan University of Medical Sciences, Rasht, Iran \\ ${ }^{5}$ Guilan Road Trauma Research Center, Guilan University of Medical Sciences, Rasht, Iran \\ ${ }^{6}$ Department of Radiology, Poursina Hospital, School of Medicine, \\ Guilan University of Medical Sciences, Rasht, Iran \\ ${ }^{7}$ Department of Neurosurgery, Poursina Hospital, School of Medicine, \\ Guilan University of Medical Sciences, Rasht, Iran
}

\begin{abstract}
Background. Stroke is the second leading cause of death and the most common debilitating neurological disorder worldwide. The ischemic injury causes inflammation and oxidative stress, and leads to apoptosis, necrosis and activation of autophagal pathways determining final infarct size. Melatonin, a hormone secreted by the pineal gland, is a small molecule that acts as a free radical scavenger, and performs antioxidant activities in several neurodegenerative diseases. Melatonin secretion reduces in aging due to pineal gland calcification and thus the calcification is a representative of reduced melatonin production. In this study, our aim was to evaluate the association of pineal gland calcification and stroke.

Material and methods. An analytical cross sectional single center study was conducted. Pineal gland calcification was assessed by CT scan in 179 patients with ischemic stroke and 177 hospital controls.

Results. The mean age in the control and stroke groups were 58.18 and 61.2 years, respectively. Pineal gland calcification was found in $77.4 \%$ of subjects in the control group and $88.8 \%$ of the subjects in the stroke group. Pineal gland calcification, alone, was shown to significantly increase the risk of ischemic stroke $(P=0.005 ; O R=2.3 ; 95 \%$ $\mathrm{Cl}=1.2-4.1)$. Furthermore, after adjustment for diabetes mellitus, hypertension, hyper lipedema, gender, and age, there was still a significant association of pineal gland calcification with ischemic stroke $(P=0.04 ; O R=2.0 ; 95 \%$ $\mathrm{Cl}=1.0-3 \cdot 9)$.

Conclusion. The evidence from the present study suggests that pineal gland calcification is associated with ischemic stroke.
\end{abstract}

Keywords: stroke, ischemic injury, pineal gland calcification, melatonin

\section{INTRODUCTION}

Stroke, observed mostly in the old (1), is a leading cause of death. Death and disability due to stroke are major concerns. Ischemic stroke is the most common type of stroke, in contrast to hemorrhagic stroke, which accounts for approximately
$10-20 \%$ of all strokes (2). Blood pressure, especially systolic blood pressure, is a major risk factor of stroke, as well as diabetes mellitus and hyperlipidemia. Two third of stroke patients show these risk factors, however, others must have other unknown risk factors (3-5). 
Inflammatory (6) and mitochondrial (7) pathways are involved in stroke. The ischemic injury causes disruption of blood brain barrier, inflammation, and oxidative stress. Brain cells can attenuate the effects of oxidative stress and are highly susceptible for oxidative damage (8). Reactive Oxygen Species (ROS), as a product of oxidative stress, damages proteins, lipids, and DNA and induces apoptosis, necrosis, and activation of autophagal pathways, which in turn determine final infarct size (9).

The pineal gland is located at the posterior part of the third ventricle. The main responsibility of the pineal gland is to secret melatonin which is a hormone regulating sleep. This small molecule acts as a free radical scavenger with antioxidant activities in many neurodegenerative diseases (10). In addition, melatonin has antioxidant and neuroprotective effects upon cerebral ischemia (11). It has potential benefits in reducing neuronal death in stroke patients through antioxidant treatment (11).

Melatonin serves its protective effect mediated through various pathways. By way of illustration, melatonin can activate nuclear factor-erythroid 2-related factor 2, which is a intracellular oxidative stress manager (12). Moreover, one of the important intracellular events during stroke is oxidative toxicity which increases ca $2+$ modulated by melatonin.88 Melatonin can also reduce apoptosis and neural cell death through PI3K/Akt cascade (1315). Melatonin reduces in aging, neurodegenerative diseases, and stroke, which-has been propounded to be caused by pineal calcification (16-19).

Brain ischemia is regulated through multiple signaling pathways result in activation of oxidative stress process, $\mathrm{Ca} 2+$ dyshomeostasis, mitochondrial dysfunction, proinflammatory mediators, excitotoxicity and/or programmed neuronal cell death; its actions to improve ischemic long-term behavioral and neuronal deficits, preserving the functional integrity of the blood-brain barrier (BBB) and improving synaptic transmission (20).

Pineal calcification happens when calcified concretions of hydroxyapatite sediment are formed. Computed tomography (CT) is used for evaluation of pineal calcification (21). Pineal calcification and subsequent reduction of melatonin production may predispose individuals to stroke (21). Moreover, therapeutic regimens with melatonin after stroke can reduce injury and improve functional outcomes $(22,23)$. According to its safety for human and ability to cross the blood-brain-barrier (BBB), it can be a potential novel therapy for ischemic stroke (11). Literature indicates controversial clinical data regarding association of pineal calcifications in various populations. In the present study, we evaluated pineal calcification as a predictor of ischemic stroke in an Iranian population.

\section{MATERIAL AND METHODS}

An analytical cross-sectional single center study was conducted in order to study the potential role of pineal gland calcification in ischemic between 2017 and 2018. Ischemic stroke patients $(\mathrm{n}=179)$ were recruited from Poursina hospital of Guilan University of Medical Sciences. Diagnosis was made using Brain CT scan imaging. Hospital controls $(n=177)$ with head trauma, without neurological and neurosurgical complications were also recruited. We collected subjects with 50-70 years of age.

Demographic characteristics of the subjects (age and gender) were collected, in addition to data on history of hypertension, diabetes mellitus, and hyperlipidemia. Pineal calcification was diagnosed using Brain CT scan. Association of pineal calcification was calculated by logistic regression analysis using STATA SE V.1. Odds ratio (OR) along with 95\% confidence interval $(95 \% \mathrm{CI})$ were also calculated.

\section{RESULTS}

The mean $\pm \mathrm{SD}$ of age was $61.23 \pm 5.5$ and $58.18 \pm 5.5$ years in the case and control groups, respectively $(\mathrm{P}=0.001)$. There was a significant difference in pineal calcification, gender, diabetes mellitus, hypertension, and hyperlipidemia between the case and control groups (Table 1).

TABLE 1. Univariate logistic regression analysis of various parameters involved in stroke

\begin{tabular}{|l|c|c|c|c|c|}
\hline Parameter & $\begin{array}{c}\text { Case } \\
\mathbf{N}(\%)\end{array}$ & $\begin{array}{c}\text { Control } \\
\mathbf{N}(\%)\end{array}$ & $\begin{array}{c}\mathbf{P} \\
\text { value }\end{array}$ & OR & $\mathbf{9 5 \%} \mathbf{C l}$ \\
\hline Pineal calcification & $159(89 \%)$ & $137(77 \%)$ & 0.005 & 2.3 & $1.2-4.1$ \\
\hline Diabetes Mellitus & $63(35 \%)$ & $33(18 \%)$ & 0.001 & 2.3 & $1.4-3.8$ \\
\hline Hypertension & $125(70 \%)$ & $53(30 \%)$ & 0.001 & 5.4 & $3.4-8.5$ \\
\hline Hyperlipidemia & $46(25 \%)$ & $18(10 \%)$ & 0.001 & 3 & $1.6-5.5$ \\
\hline Gender (Female) & $85(47 \%)$ & $70(39 \%)$ & 0.13 & 0.7 & $0.4-1.1$ \\
\hline Age & - & - & 0.001 & 1.1 & $1.0-1.1$ \\
\hline
\end{tabular}


TABLE 2. Multivariate logistic regression analysis of various parameters involved in stroke

\begin{tabular}{|l|c|c|c|}
\hline Parameter & P value & OR & 95\% Cl \\
\hline Pineal calcification & 0.04 & 2.0 & $1.0-3.9$ \\
\hline Diabetes Mellitus & 0.32 & 1.3 & $0.7-2.3$ \\
\hline Hypertension & 0.001 & 5.4 & $2.3-6.2$ \\
\hline Hyperlipidemia & 0.09 & 3 & $0.9-3.5$ \\
\hline Gender & 0.85 & 0.9 & $0.6-1.5$ \\
\hline Age & 0.001 & 2 & $1.0-1.1$ \\
\hline
\end{tabular}

Table 2 illustrates multivariate logistic regression parameters involved in stroke. After adjustment for diabetes mellitus, hypertension, hyper lipedema, gender, and age, there was a significant association between pineal calcification and stroke $(\mathrm{P}=0.04)$.

\section{DISCUSSION}

Stroke is one of the most common life-threatening neurological disorders and a leading cause of disability (24). It mostly affects the elderly causing a significant burden to their family (25). Melatonin has antioxidant activities useful against ischemic injuries. It has been used against as a therapeutic agent ischemic brain injury (20). In the present study, we studied association of pineal calcification and ischemic stroke in an Iranian population.

Our study showed that $77 \%$ of the hospital control group had pineal calcification. Daghighi et al. (26) reported that $71 \%$ of patients with trauma had pineal calcification in their brain CT scan. Moreover, Yalcin et al. (27) studied 12,000 Turkish patients without any pathologic lesion and reported pineal calcification in $71.6 \%$ of the subjects.

We found that gender was not associated with ischemic stroke in the studied population. However, age, hypertension, and hyperlipidemia were demonstrated to have an association with ischemic stroke. In our investigation, pineal calcification, alone, was shown to significantly increase the risk of ischemic stroke. Furthermore, after adjustment for diabetes mellitus, hypertension, hyper lipedema, gender, and age, there was still a significant association of pineal gland calcification with ischemic

\section{REFERENCES}

1. Talebi M, Ghertasi M, Taheraghdam A, Andalib S, Sharifipour E. A comparison of risk factors and severity of ischemic stroke in female and male genders in North-West Iran: A cross-sectional study. Iranian Journal of Neurology. 2014;13(4):215-9. stroke.

Our finding was in agreement with those of Kitkhuandee et al. (21) studying association of pineal calcification and symptomatic cerebral infarction in 620 Thai patients. In their study, by univariate logistic regression was used and age of more than 50 years, hypertension, diabetes, dyslipidemia, and pineal calcification were significantly related to cerebral infarction. Moreover, pineal calcification as a risk factor of cerebral infarction showed an adjusted OR of 1.35 (95\% CI=1.05-1.72).

Kitkhuandee et al. (28) investigated 1071 Brain CT scans of patients with symptomatic intracerebral hemorrhage and evaluated the association of and pineal calcification and the disease. Intracerebral hemorrhage and pineal calcification were observed in $77(7.2 \%)$ and $689(64.3 \%)$ of Thai patients, respectively. The authors pointed out that pineal calcification is a significant risk factor of intracerebral hemorrhage $(\mathrm{OR}=2.36 ; 95 \% \mathrm{CI}=1.22$ 4.54). Moreover, age of more than 50 years, hypertension, and diabetes, were found to be associated with the disease.

On the other hand, Del Brutto et al. (29) tested the hypothesis of the association of pineal calcification and stroke in a population-based study in Ecuador. Pineal calcification was found in $61 \%$ versus $54 \%$ of individuals with and without stroke, respectively. After adjustment for age, sex and cardiovascular health, no association was observed between any evidence $(p=0.916)$ or severity $(p=0.740)$ of pineal calcification and the disease.

\section{CONCLUSION}

Altogether, the evidence from the present study suggests that pineal calcification is associated with stroke and has a predictive value in this regard. Therefore, we suggest that clinicians attend to the imaging evidence of pineal calcification in CT scans. Further investigation is required to assess the predictive role of pineal calcification size and severity of ischemic injury.

\section{Conflict of interest: none declared} Financial support: none declared

2. Tibæk M, Dehlendorff C, Jørgensen HS, Forchhammer HB, Johnsen SP, Kammersgaard LP. Increasing Incidence of Hospitalization for Stroke and Transient Ischemic Attack in Young Adults: A RegistryBased Study. J Am Heart Assoc. 2016;5(5):e003158. 
3. Toole JF, Murros K, Veltkamp R. Cerebrovascular disorders: Lippincott Williams \& Wilkins; 1999.

4. Whisnant JP. Modeling of risk factors for ischemic stroke. Stroke. 1997;28(9):1840-4.

5. Michael J AD, David A, Greenburg, Roger P, Simon. Clinical Neurology. New York, 2002.

6. Shaafi S, Sharifipour E, Rahmanifar R, Hejazi S, Andalib S, Nikanfar $\mathrm{M}$, et al. Interleukin-6, a reliable prognostic factor for ischemic stroke. Iranian Journal of Neurology. 2014;13(2):70-6.

7. Andalib S, Divani AA, Michel TM, Høilund-Carlsen PF, Vafaee MS, Gjedde A. Pandora's Box: mitochondrial defects in ischaemic heart disease and stroke. Expert Reviews in Molecular Medicine. 2017;19(e5):1-20.

8. Andrabi SS, Parvez S, Tabassum H. Melatonin and ischemic stroke: mechanistic roles and action. Advances in Pharmacological Sciences. 2015;2015.

9. Rodrigo R, Fernández-Gajardo R, Gutiérrez R, Manuel Matamala J, Carrasco R, Miranda-Merchak A, et al. Oxidative stress and pathophysiology of ischemic stroke: novel therapeutic opportunities. CNS \& Neurological Disorders-Drug Targets (Formerly Current Drug Targets-CNS \& Neurological Disorders). 2013;12(5):698-714.

10. Wang $X$. The antiapoptotic activity of melatonin in neurodegenerative diseases. CNS Neuroscience \& Therapeutics. 2009;15(4):345-57.

11. Wang X, Figueroa BE, Stavrovskaya IG, Zhang Y, Sirianni AC, Zhu S, et al. Methazolamide and melatonin inhibit mitochondrial cytochrome $\mathrm{C}$ release and are neuroprotective in experimental models of ischemic injury. Stroke. 2009;40(5):1877-85.

12. Parada E, Buendia I, León R, Negredo P, Romero A, Cuadrado A, et al. Neuroprotective effect of melatonin against ischemia is partially mediated by alpha-7 nicotinic receptor modulation and HO-1 overexpression. Journal of Pineal Research. 2014;56(2):204-12.

13. Pandi-Perumal SR, BaHammam AS, Brown GM, Spence DW, Bharti VK, Kaur C, et al. Melatonin antioxidative defense: Therapeutical implications for aging and neurodegenerative processes. Neurotoxicity Research. 2013;23(3):267-300.

14. Feng Y, Lu S, Wang J, Kumar P, Zhang L, Bhatt AJ. Dexamethasoneinduced neuroprotection in hypoxic-ischemic brain injury in newborn rats is partly mediated via Akt activation. Brain Research. 2014;1589:68-77.

15. Juan WS, Huang SY, Chang CC, Hung YC, Lin YW, Chen TY, et al. Melatonin improves neuroplasticity by upregulating the growthassociated protein-43 (GAP-43) and NMDAR postsynaptic density-95 (PSD-95) proteins in cultured neurons exposed to glutamate excitotoxicity and in rats subjected to transient focal cerebral ischemia even during a long-term recovery period. Journal of Pineal Research. 2014;56(2):213-23.

16. Zhou JN, Liu RY, Heerikhuize J, Hofman MA, Swaab DF. Alterations in the circadian rhythm of salivary melatonin begin during middleage. Journal of Pineal Research. 2003;34(1):11-6.
17. Mahlberg R, Tilmann A, Salewski L, Kunz D. Normative data on the daily profile of urinary 6 -sulfatoxymelatonin in healthy subjects between the ages of 20 and 84. Psychoneuroendocrinology. 2006; 31(5):634-41.

18. Ritzenthaler T, Nighoghossian N, Berthiller J, Schott AM, Cho TH, Derex L, et al. Nocturnal urine melatonin and 6-sulphatoxymelatonin excretion at the acute stage of ischaemic stroke. Journal of Pineal Research. 2009;46(3):349-52.

19. Zimmerman R, Bilaniuk L. Age-related incidence of pineal calcification detected by computed tomography. Radiology. 1982; 142(3):659-62.

20. Ramos E, Patino P, Reiter RJ, Gil-Martin E, Marco-Contelles J, Parada $E$, et al. Ischemic brain injury: new insights on the protective role of melatonin. Free Radical Biology and Medicine. 2017; 104:32-53.

21. Kitkhuandee A, Sawanyawisuth K, Johns NP, Kanpittaya J, Johns J. Pineal calcification is associated with symptomatic cerebral infarction. Journal of Stroke and Cerebrovascular Diseases. 2014;23(2):249-53.

22. Mahlberg R, Kienast T, Hädel S, Heidenreich JO, Schmitz S, Kunz D. Degree of pineal calcification (DOC) is associated with polysomnographic sleep measures in primary insomnia patients. Sleep Medicine. 2009;10(4):439-45.

23. Macleod MR, O'collins T, Horky LL, Howells DW, Donnan GA. Systematic review and meta-analysis of the efficacy of melatonin in experimental stroke. Journal of Pineal Research. 2005;38(1):35-41.

24. Azarpazhooh MR, Etemadi MM, Donnan GA, Mokhber N, Majdi MR, Ghayour-Mobarhan M, et al. Excessive incidence of stroke in Iran: evidence from the Mashhad Stroke Incidence Study (MSIS), a population-based study of stroke in the Middle East. Stroke. 2010; 41(1):e3-e10.

25. Kavian G. Diagnosis, management and prevention of ischemic stroke for non-neurologists. Zahedan Journal of Research in Medical Sciences. 2011;13(3):1-8.

26. Daghighi M, Rezaei V, Zarrintan S, Pourfathi H. Intracranial physiological calcifications in adults on computed tomography in Tabriz, Iran. Folia Morphologica. 2007;66(2):115-9.

27. Yalcin A, Ceylan M, Bayraktutan OF, Sonkaya AR, Yuce I. Age and gender related prevalence of intracranial calcifications in CT imaging; data from 12,000 healthy subjects. Journal of Chemical Neuroanatomy. 2016;78:20-4.

28. Kitkhuandee A, Sawanyawisuth K, Johns J, Kanpittaya J, Tuntapakul $\mathrm{S}$, Johns NP. Pineal calcification is a novel risk factor for symptomatic intracerebral hemorrhage. Clinical Neurology and Neurosurgery. 2014;121:51-4.

29. Del Brutto OH, Mera RM, Lama J, Zambrano M. Stroke and pineal gland calcification: lack of association. Results from a populationbased study (The Atahualpa Project). Clinical Neurology and Neurosurgery. 2015;130:91-4. 